\title{
Review of heavy-ion induced desorption studies for particle accelerators
}

\author{
Edgar Mahner* \\ CERN, Accelerator Technology Department, Vacuum Group, 1211 Geneva 23, Switzerland
}

(Received 25 August 2008; published 29 October 2008)

\begin{abstract}
During high-intensity heavy-ion operation of several particle accelerators worldwide, large dynamic pressure rises of orders of magnitude were caused by lost beam ions that impacted under grazing angle onto the vacuum chamber walls. This ion-induced desorption, observed, for example, at CERN, GSI, and BNL, can seriously limit the ion intensity, luminosity, and beam lifetime of the accelerator. For the heavyion program at CERN's Large Hadron Collider collisions between beams of fully stripped lead ${ }^{208} \mathrm{~Pb}^{82+}$ ) ions with a beam energy of $2.76 \mathrm{TeV} / \mathrm{u}$ and a nominal luminosity of $10^{27} \mathrm{~cm}^{-2} \mathrm{~s}^{-1}$ are foreseen. The GSI future project FAIR (Facility for Antiproton and Ion Research) aims at a beam intensity of $10^{12}$ uranium $\left({ }^{238} \mathrm{U}^{28+}\right)$ ions per second to be extracted from the synchrotron SIS18. Over the past years an experimental effort has been made to study the observed dynamic vacuum degradations, which are important to understand and overcome for present and future particle accelerators. The paper reviews the results obtained in several laboratories using dedicated test setups, the mitigation techniques found, and their implementation in accelerators.
\end{abstract}

DOI: 10.1103/PhysRevSTAB.11.104801

\section{INTRODUCTION}

The effect of ions on the dynamic vacuum of a particle accelerator dates back to 1973 where a so-called ioninduced vacuum instability was first observed in the Intersecting Storage Rings (ISR) at CERN [1]. The circulating proton beam ionized residual gas molecules, which were accelerated by the beam potential, bombarded the vacuum chamber walls and released gas adsorbed on the surface. Above a critical beam current the vacuum system became unstable and limited the ISR beam intensity. It was found that the ion-desorption yield strongly depended on the cleanliness of the vacuum chamber walls. A combination of increased pumping speed, improved bakeouts, special vacuum chamber surface treatments, including argon glow-discharge cleaning, coatings (gold, silver, titanium), and oxidation, helped to stabilize the ISR vacuum system [2]. A different type of vacuum instability, induced by the loss of heavy ions, was first observed in 1997 during $\mathrm{Pb}^{54+}$ accumulation and cooling tests in the Low Energy Antiproton Ring (LEAR) at CERN [3]. A dynamic beaminduced pressure rise limited the beam lifetime and the intensity in LEAR. The vacuum degradation was not understood at that time. Similar observations were reported in 1998 from the Alternate Gradient Synchrotron (AGS) Booster in Brookhaven (BNL) where lost $\mathrm{Au}^{31+}$ ions produced significant local pressure bumps [4,5]. In 2001 a vacuum pressure increase was observed during a highintensity $\mathrm{U}^{28+}$ run in the heavy-ion synchrotron SIS 18 at GSI [6]. It was found that the beam lifetime was no longer independent of the injected ion current and that injection losses, either at the vacuum chamber wall or at aperture limiting devices, were responsible for large pressure ex-

\footnotetext{
*Edgar.Mahner@cern.ch
}

PACS numbers: 29.27.-a, 79.20.Rf, 34.50.Bw, 41.75.Ak

cursions [6,7]. The Relativistic Heavy Ion Collider (RHIC) at BNL started operation in 2000; since 2001 dynamic pressure rises were observed that limited the intensity of the $\mathrm{Au}^{79+}$ beam [8]. Although molecular desorption from beam losses was initially suspected to contribute significantly to the observed dynamic pressure rises in RHIC, it was later concluded that all pressure rises relevant for the accelerator operation are caused by the electron cloud effect [9]. Ion beam-induced pressure rises may also limit the performance of future high-intensity heavy-ion linear accelerators which could be used as drivers for heavy-ion inertial fusion [10]. A High-Current Experiment (HCX) was performed at the Lawrence Berkeley National Laboratory (LBNL) to study the transport dynamics of a rather low-energy but high-intensity $\mathrm{K}^{+}$ion beam and gas desorption coefficients were reported in 2004 [11].

Today, the observed ion-impact induced molecular desorption is still a serious problem especially for accelerators which operate with intermediate charge state heavyion beams. These not fully stripped ions can change their charge state due to interaction with the residual gas. The charge-exchanged ions then follow a different trajectory which finally results in beam loss onto the vacuum chamber walls. This ion bombardment, which often happens under grazing angle impact, increases the dynamic pressure and causes further ion losses, which can lead to avalanchelike dynamic pressure rises often limiting the performance of the accelerator. In contrast to the lowenergy ion-desorption coefficients measured at the ISR, several orders of magnitude larger desorption yields were reported from different accelerator laboratories worldwide [12].

The objective of this paper is to review desorption experiments with heavy-ion accelerators, in particular to summarize experimental setups and methods, beam types, 
and targets used. Afterwards, examples for pressure rise measurements and surface characterizations are presented, the ion-impact angle, charge state, and energy dependence on the measured desorption yield as well as some mitigation techniques for particle accelerators are reviewed.

\section{EXPERIMENTS}

\section{A. Motivation for desorption experiments}

As already indicated above, the motivation to study the molecular desorption induced by heavy ions has been triggered about one decade ago by the observation of dynamic vacuum effects in heavy-ion accelerators strongly affecting the machine operation; this includes, for example, very strong pressure rises, limited beam intensities, and reduced beam lifetimes.

More specifically, in preparation of the heavy-ion physics with the Large Hadron Collider (LHC) at CERN, an upgrade of the ion injector chain was required where the LEAR machine had to be converted into a Low Energy Ion Ring (LEIR). In order to obtain the demanding average dynamic pressure of $3 \times 10^{-12}$ Torr, required around the LEIR ring to satisfy the requested beam lifetime [13], beam-loss induced molecular desorption was intensively studied at CERN's Heavy Ion Accelerator (LINAC 3) since late 2000. The experiments mainly aimed to quantify the desorption yields for $4.2 \mathrm{MeV} / \mathrm{u}$ lead ions and to find pragmatic solutions to overcome this potential limitation for the LEIR vacuum system. The LEIR vacuum requirements, design, and challenges are described elsewhere [14]. At GSI, the FAIR project [15] is designed to deliver heavy-ion beams with an increased intensity $\left(\approx 10^{3}\right.$ for primary and $\approx 10^{4}$ for secondary beams) compared to the existing GSI accelerator facilities. Beam-loss and ioninduced desorption are a serious intensity limitation in SIS 18 [16-19], which is part of the FAIR injector chain. Therefore, experiments at GSI were mainly motivated by the operation and necessary upgrade of SIS 18 and the construction of FAIR. At BNL most of the experimental studies were performed due to operational problems first observed in the AGS Booster [4,5] and later in RHIC [8,20-23], which also triggered machine upgrades by the installation of getter coated beam pipes [24], and the study of antigrazing rings [25] in RHIC. Measurements at LBNL [11] and TSL [26] could be characterized as development work for future projects, either for heavy-ion drivers or synchrotrons.

\section{B. Experimental setups, targets, and test stands}

The experimental setups used in the different laboratories can be classified in two types: first, purpose-built experiments that have been installed at accelerator beam lines like LINAC 3 [27-31] and SPS [32] at CERN, HLI $[33,34]$ and HHT [35,36] at GSI, TSL [26] at Uppsala, HCX at LBNL and STS-500 at LLNL [37], and Tandem [38] at BNL; second, studies at synchrotrons either during normal machine operation or machine developments, for example LEAR [3] at CERN, SIS 18 [6,39,40] at GSI, AGS Booster [4,5], and RHIC [23] at BNL. Ion-desorption machine studies with synchrotrons are described in detail in the literature; here we focus on dedicated setups used at beam lines.

Basically, two different target types have been chosen for beam line desorption studies, either accelerator-type vacuum chamber bombarded with heavy ions under grazing impact angles (LINAC 3, Tandem), or small-sized flat samples, including ultrahigh-vacuum Conflat ${ }^{\mathrm{TM}}$ flanges, irradiated either under perpendicular impact (HLI, HHT, TSL) or under grazing angles (SPS, HCX, STS-500). Typical examples are shown in Fig. 1, where the layout of the CERN and GSI test stands are sketched. Both experiments can be separated from the accelerators by sector valves to allow target changes and vacuum conditioning without affecting the machine operation. The experiments are bakable to measure ion desorption under ultrahigh vacuum (UHV) conditions using standard UHV instrumentation like Bayard-Alpert (BAG) and extractor gauges and residual gas analyzers (RGA).

\section{Experimental methods}

The measurement techniques used are described in detail elsewhere [30,35,41]. In most cases the determination of the desorption yields is based on measuring the pressure rise either during continuous heavy-ion bombardment or with single shots. The single shot technique, first applied
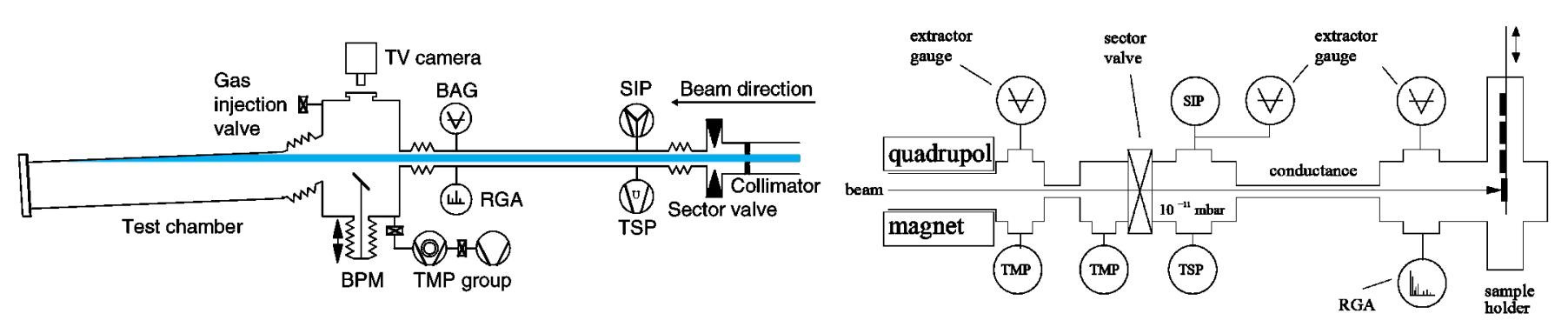

FIG. 1. (Color) Experimental setups used for heavy-ion-induced desorption studies at the CERN Heavy Ion Accelerator LINAC 3 (left) and in the HHT cave of SIS 18 at GSI (right) [30,35]. 
for heavy ions at CERN, has the advantage that ioninduced surface modifications can be minimized while with the continuous bombardment the cleaning effect, often called beam scrubbing, can be investigated. Briefly, the effective ion-induced desorption yield $\eta_{\text {eff }}$ (molecules/ion) is given by the conductance method, i.e.,

$$
\eta_{\mathrm{eff}}=\frac{\Delta P \times S}{\dot{N} \times k_{B} \times T}=G \times \frac{\Delta P \times S}{\dot{N}},
$$

where $\Delta P$ is the partial pressure increase in the test chamber under ion bombardment, $S$ is the pumping speed in $\ell / \mathrm{s}$, $\dot{N}$ is the number of impacting ions per second, $k_{B}$ is the Boltzmann constant, $T$ is the temperature ( $300 \mathrm{~K})$, and $G$ is a constant, which converts gas quantities into number of molecules. Formula (1) has been widely used to determine desorption yields. In addition, the effective desorption yields $\eta_{\text {eff,ss }}$ can be measured using single shots of heavy ions:

$$
\eta_{\mathrm{eff}, \mathrm{ss}}=\frac{\Delta P \times V}{N \times k_{B} \times T}=G \times \frac{\Delta P \times V}{N},
$$

where $\Delta P$ is the partial pressure increase in the test chamber after one shot, $V$ is the test volume, and $N$ is the number of impacting ions. Apart from LINAC 3 experiments, this technique has been much less used in other laboratories. Pressure rise measurements of both types can be found in the literature $[30,42]$.

\section{Ion beams, energies, and target materials}

Desorption measurements with heavy ions in the energy range of $\approx 1 \mathrm{MeV} / \mathrm{u}$ to $\approx 100 \mathrm{GeV} / \mathrm{u}$ depend on existing accelerators which have in general not much flexibility in changing the type, energy, and charge state of the ions. Therefore, a large variety of beams have been used in different laboratories, which are summarized in Table I.

One finds that most of the used projectiles are not fully stripped, except for the high-energy ion beams of the SPS and RHIC accelerators. The beam energies are either around the Bragg peak or very much above; only the potassium beam energy is well below the Bragg peak. For the projectile impact angles there are two families of experiments, either grazing impact angles as they occur after charge-changing processes in an accelerator or perpendicular impact. There is also a large variation in studied target materials but with a focus on stainless steel, which is one of the most common vacuum chamber materials for the construction of UHV systems. In addition, many different surface treatments like glow discharges, chemical polishing and electropolishing, high-temperature vacuum firing

TABLE I. Overview of heavy-ion-induced desorption experiments at particle accelerators worldwide. The different types of ions, charge states, energies, impact angles, and target materials are compared between the different laboratories. Desorption experiments

\begin{tabular}{|c|c|c|c|c|c|}
\hline Projectile & Ion energy & Impact angle & $\begin{array}{l}\text { Target material, } \\
\text { Stainless steel = ss }\end{array}$ & Lab-Accelerator & Reference \\
\hline $\mathrm{Au}^{31+}$ & $1 \mathrm{MeV} / \mathrm{u}$ & Grazing & Stainless steel & BNL-AGS & {$[4,5]$} \\
\hline $\begin{array}{l}\mathrm{Au}^{79+} \\
\mathrm{Au}^{79+} \\
\mathrm{Cu}^{29+} \\
\mathrm{p}^{+}\end{array}$ & $\begin{array}{l}8.9 \mathrm{GeV} / \mathrm{u} \\
9 \mathrm{GeV} / \mathrm{u} \\
10 \mathrm{GeV} / \mathrm{u} \\
23 \mathrm{GeV}\end{array}$ & $\begin{array}{l}\text { Grazing } \\
\text { Perpendicular } \\
\text { Perpendicular } \\
\text { Perpendicular }\end{array}$ & $\begin{array}{l}\text { Stainless steel } \\
\text { Stainless steel } \\
\text { Stainless steel } \\
\text { Stainless steel }\end{array}$ & BNL-RHIC & $\begin{array}{l}{[22]} \\
{[23]}\end{array}$ \\
\hline $\mathrm{Pb}^{53+} / \mathrm{Pb}^{27+}$ & $4.2 \mathrm{MeV} / \mathrm{u}$ & $\begin{array}{l}\text { Grazing and } \\
\text { perpendicular }\end{array}$ & $\begin{array}{l}\text { ss }(316 \mathrm{LN}, 304 \mathrm{~L}) \\
\mathrm{Au}, \mathrm{Ag}, \mathrm{Pd}, \mathrm{TiZrV} / \mathrm{ss}(316 \mathrm{LN}) \\
\mathrm{Cu}, \mathrm{Al}, \mathrm{Mo}, \mathrm{Si} / \mathrm{ss}(316 \mathrm{LN})\end{array}$ & CERN-LINAC 3 & {$[30,31]$} \\
\hline $\mathrm{In}^{49+}$ & $158 \mathrm{GeV} / \mathrm{u}$ & Grazing & $\begin{array}{l}\text { ss (316LN), graphite, } \\
\mathrm{Cu} / \text { graphite, TiZrV/graphite }\end{array}$ & CERN-SPS & {$[32,43]$} \\
\hline $\begin{array}{l}\mathrm{C}^{2+}, \mathrm{Cr}^{7+} \\
\mathrm{Pb}^{27+}, \mathrm{Zn}^{10+} \\
\mathrm{Xe}^{18+\cdots 21+}\end{array}$ & $1.4 \mathrm{MeV} / \mathrm{u}$ & $\begin{array}{l}\text { Perpendicular } \\
19^{\circ} \text { (ERDA) }\end{array}$ & $\begin{array}{l}\text { ss }(304 \mathrm{~L}, 316 \mathrm{LN}), \\
\mathrm{Cu}, \mathrm{Si}, \mathrm{Al} \\
\text { ss }(304 \mathrm{~L}, 316 \mathrm{LN}), \\
\mathrm{Cu}, \mathrm{Au} / 316 \mathrm{LN}, \mathrm{Au} / \mathrm{Cu}, \mathrm{Rh} / \mathrm{Cu}\end{array}$ & GSI-HLI & $\begin{array}{c}{[33,44]} \\
{[45]}\end{array}$ \\
\hline $\mathrm{U}^{28+}$ & $8.9 \mathrm{MeV} / \mathrm{u}$ & Grazing & ss $(316 \mathrm{LN})$ & GSI-SIS 18 & [7] \\
\hline $\begin{array}{l}\mathrm{U}^{73+} \\
\mathrm{Ar}^{10+}\end{array}$ & $\begin{array}{l}15,40,100 \mathrm{MeV} / \mathrm{u} \\
40,80,100 \mathrm{MeV} / \mathrm{u}\end{array}$ & Perpendicular & $\begin{array}{l}\text { ss }(316 \mathrm{LN}, \mathrm{P} 506) \\
\text { ss }(316 \mathrm{LN}), \mathrm{Cu}, \mathrm{Al}\end{array}$ & GSI-HHT & $\begin{array}{l}{[36]} \\
{[46]}\end{array}$ \\
\hline$\overline{\mathrm{K}^{+}}$ & $0.002-0.025 \mathrm{MeV} / \mathrm{u}$ & Grazing & Stainless steel & $\begin{array}{c}\text { LBNL-HCX } \\
\text { LLNL-STS500 }\end{array}$ & {$[37,41]$} \\
\hline $\mathrm{Ar}^{8+} / \mathrm{Ar}^{9+} / \mathrm{Ar}^{12+}$ & $5,9.7,17.7 \mathrm{MeV} / \mathrm{u}$ & Perpendicular & ss $(316 \mathrm{LN}), \mathrm{Cu}, \mathrm{Ta}$ & Uppsala-TSL & [47] \\
\hline
\end{tabular}
were performed between 1998 and 2008. 
at $950^{\circ} \mathrm{C}$, in situ bakeouts up to $400^{\circ} \mathrm{C}$, and several coatings (noble metals and getters) of stainless steel have been tested for desorption at CERN.

\section{RESULTS}

\section{A. Pressure rise measurements}

A typical example for a summary of various pressure rise measurements is shown in Fig. 2. Lead ions with an energy of $4.2 \mathrm{MeV} / \mathrm{u}$ bombarding differently prepared accelerator-type vacuum chambers under $\theta=89.2^{\circ}$ grazing incidence angle had been used [30,31]. Figure 2 illustrates that the heavy-ion-induced desorption yield depends very critically on the upper surface properties of the targets, which was not a surprise after the observation made in the ISR. The strong influence of the stainless steel surface properties and the effect of noble metal and getter coatings are clearly visible. The oxide layer thickness and the quantity of adsorbed molecules, especially carbon and oxygen, had been suspected [30] to play an important role for the molecular desorption of heavy ions and motivated our measurements with $\mathrm{Au}, \mathrm{Ag}, \mathrm{Pd}$ coated stainless steel chambers as well as the investigations of nonevaporable getter (NEG) TiZrV coatings. A detailed description of the surface preparations, experimental results on single shot and scrubbing measurements, as well as x-ray photoemission spectroscopy (XPS) results are published elsewhere [31].

\section{B. Surface characterization}

Measurements with calibrated residual gas analyzers have shown that the dominant gases desorbed by lead ions were $\mathrm{CO}, \mathrm{CO}_{2}$, and $\mathrm{H}_{2}$ [30,31]. Similar results have been obtained with $1.4 \mathrm{MeV} / \mathrm{u}$ Xe ions at GSI [48]. It was concluded that some correlation seems to exist between the level of surface contamination and the initial pressure rise. Therefore, XPS and ERDA (Elastic Recoil Detection Analysis) measurements were performed with samples cut out from tested LINAC 3 vacuum chambers. The results are shown in Fig. 3. A clear correlation was found between the surface oxygen and carbon content and the measured pressure rises $\Delta P$, which is proportional to the ion-induced desorption yield $\eta$. This confirmed the expectation that surface properties of vacuum chambers or other aperture limiting devices play an important role for the pressure rises observed in particle accelerators.

To obtain a better understanding of the physical processes behind the heavy-ion beam-loss induced desorption, yield measurements have been combined with the in situ

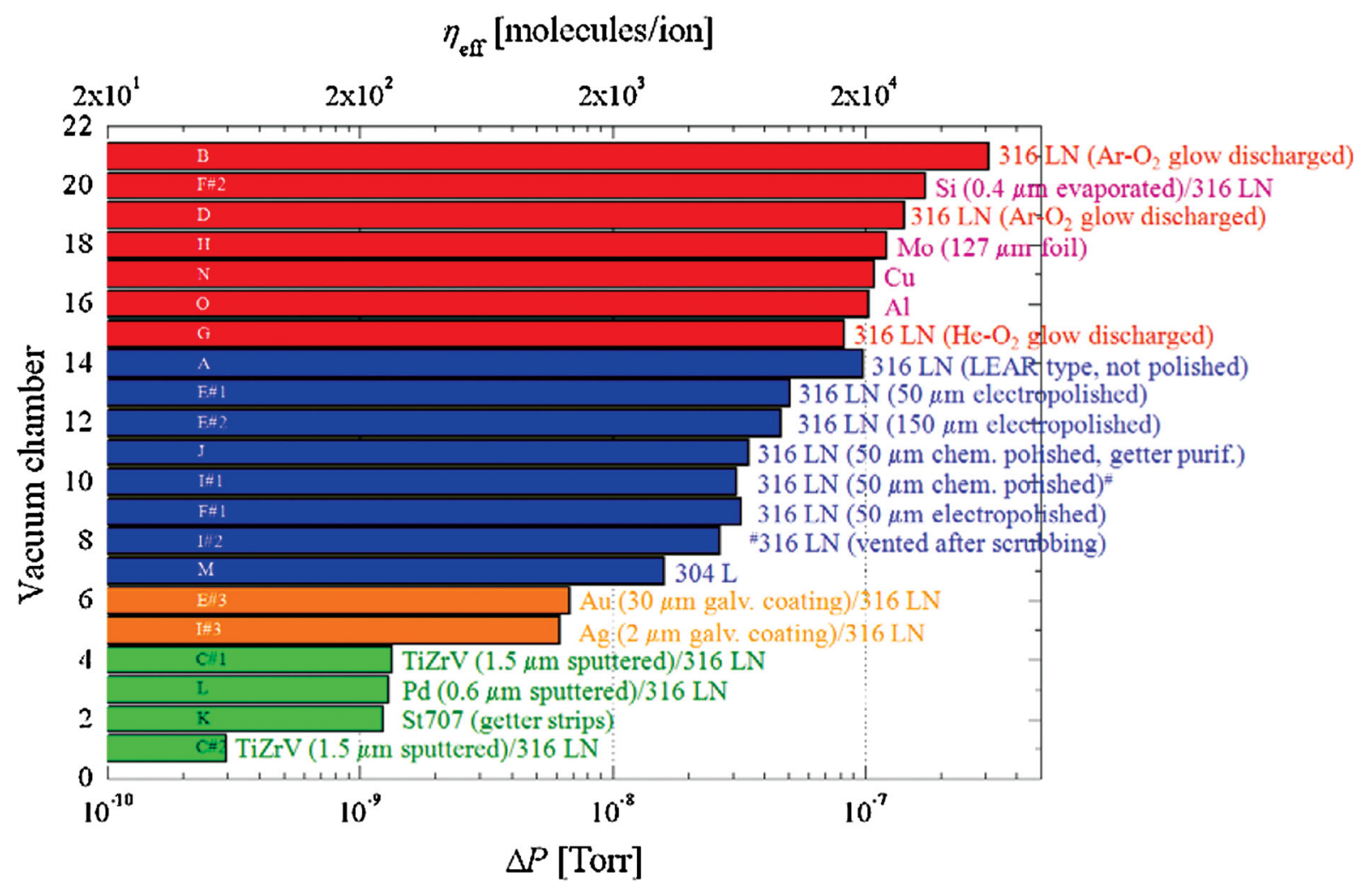

FIG. 2. (Color) Summary of pressure rise measurements for 21 different surfaces (15 different vacuum chambers) continuously bombarded with $\sim 1.5 \times 10^{9} \mathrm{~Pb}^{53+}$ ions under $\theta=89.2^{\circ}$ grazing incidence. The pressure increase $\Delta P$ is measured at the beginning of each scrubbing run. The plot summarizes LINAC 3 results obtained between November 2000 and October 2002 [30,31], new results obtained for bulk $\mathrm{Al}$ and $\mathrm{Cu}$ vacuum chambers, a Mo liner and evaporated Si on stainless steel are added. 

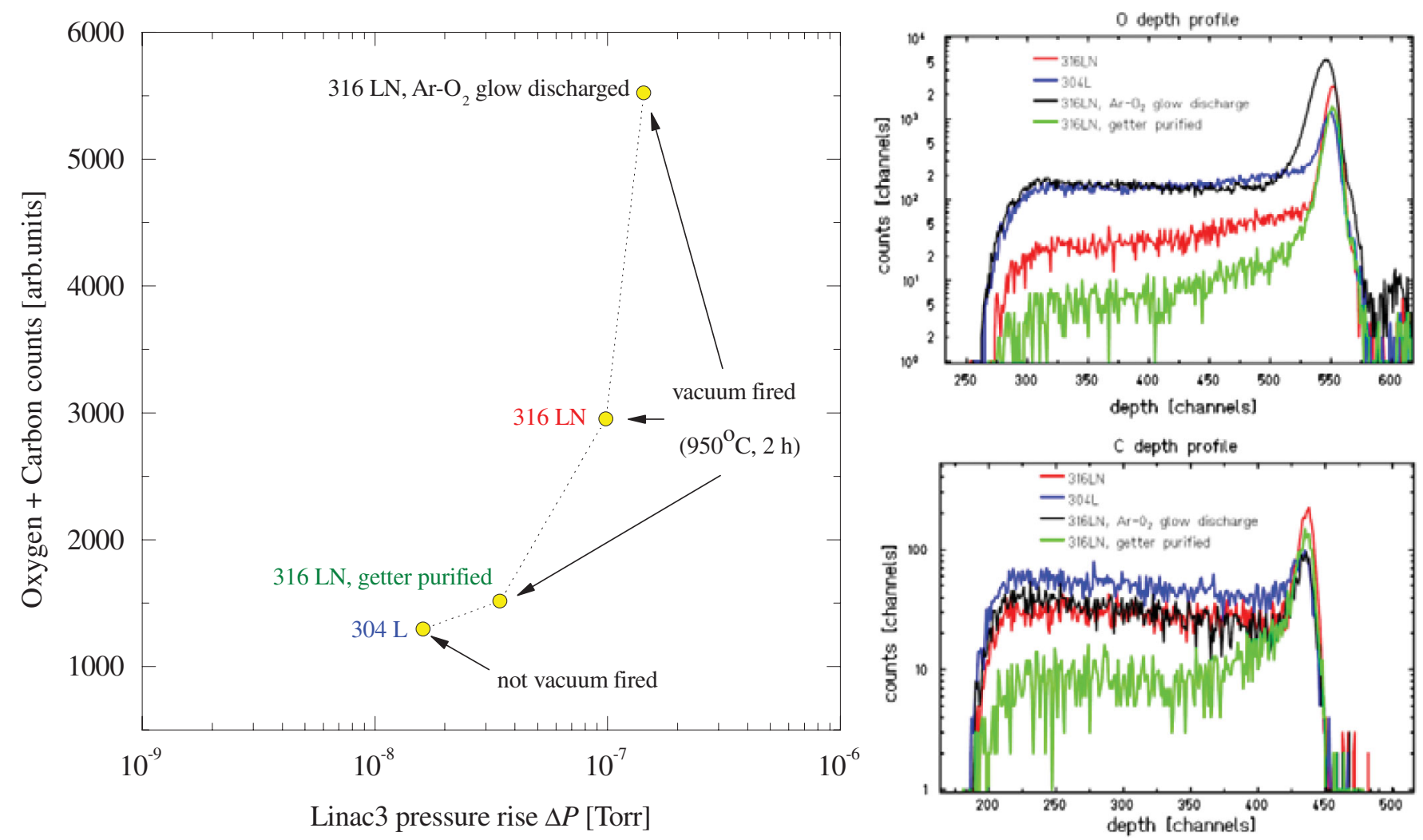

FIG. 3. (Color) Left: LINAC 3 pressure rises versus oxygen and carbon content of test samples analyzed with ERDA, the spectra are shown on the right side. Desorption measurements were done with $4.2 \mathrm{MeV} / \mathrm{u}$ lead ions at CERN, then the 4 vacuum chambers were cut and samples studied with ERDA at the Munich Tandem Accelerator using $1 \mathrm{MeV} / \mathrm{u} \mathrm{Au}^{+30}$ ions [70].

analysis technique ERDA [49]. It was found that the desorption behavior of samples can be correlated to their surface and bulk properties. A detailed description of the experimental setup used at GSI, the projectiles/targets, and the results can be found elsewhere [45].

\section{Impact angle and charge state dependence}

The secondary electron yield (SEY) of stainless steel surfaces and their dependence on the angle of incidence was researched for 28-MeV protons, 126-MeV oxygen ions, and 182-MeV gold ions at BNL [50]. A near $1 / \cos (\theta)$ behavior was found between $0^{\circ}$ and $89^{\circ}$. For a $1 \mathrm{MeV} / \mathrm{u}$ gold beam large grazing incidence yields of up to $\approx 33000$ electrons per ion were measured. These data suggested in some way a similar dependence of the heavyion-induced desorption yield.

With heavy ions, the projectile impact angle dependence on the desorption yields was measured under UHV conditions for $\mathrm{Pb}^{27+}$ and $\mathrm{Pb}^{53+}$ ions $(4.2 \mathrm{MeV} / \mathrm{u})$ impacting under various angles $\left[\theta=0^{\circ}\right.$ (perpendicular), 84.8 $89.2^{\circ}$ ] onto vacuum chambers at LINAC 3 [30]. Measurements with $158 \mathrm{GeV} / \mathrm{u} \mathrm{In}^{49+}$ ions bombarding collimator-type samples $\left(\theta=88.3^{\circ}\right)$ were done at the SPS [32]. Low-energy $(0.025 \mathrm{MeV} / \mathrm{u}) \mathrm{K}^{+}$ions were used to study the angle dependence $\left(\theta=80-88^{\circ}\right)$ using a stainless steel plate of the so-called GESD (gas-electron source diagnostic) placed in a high-vacuum chamber [41]. It was found that the grazing impact of lead ions desorbed more molecules than less grazing or even perpendicular impact. The desorption yield difference, measured between $84.8^{\circ}$ and $89.2^{\circ}$, was less significant than one would have expected according to a $1 / \cos (\theta)$ scaling found for the SEY of ions. A similar behavior was measured with $\mathrm{K}^{+}$ ions [37,41]. In both experiments the yields varied only little with the ion-impact angle. One has to keep in mind that such experiments are quite difficult to perform, especially for very small accelerator-relevant impact angles $\left(\theta>89.5^{\circ}\right)$ due to the necessary length of either test vacuum chambers or samples, due to alignment errors of the targets, and due to the surface roughness which becomes relevant for small impact angles. In that regime the surface morphology cannot be neglected anymore because impacting projectiles, especially heavy ions, can traverse several surface peaks and release gas molecules before they penetrate into the bulk of the target. This has been explicitly demonstrated with simulation studies and RHIC beam pipe roughness measurements [25].

Anyhow, from the described experiments one has taken the conclusion that lost beam ions should bombard special low-outgassing absorbers preferentially under perpendicu- 
lar impact [13], a concept that has been first applied for the ion-loss collimation system [51] in the LEIR vacuum system [14].

The desorption yields of heavy ions with a fixed energy but a different charge state has been investigated at LINAC 3 [30]. Several vacuum chambers were bombarded with 4. $2 \mathrm{MeV} / \mathrm{u} \mathrm{Pb}^{27+}$ and $\mathrm{Pb}^{53+}$ ions, either under perpendicular or grazing angle impact. The largest yield difference, about a factor of 10 , was found for a vacuum fired $\left(950^{\circ} \mathrm{C}, 2 \mathrm{~h}\right)$ and in situ baked $\left(300^{\circ} \mathrm{C}, 24 \mathrm{~h}\right)$ bare stainless steel vacuum chamber which was bombarded with $\mathrm{Pb}^{27+}$ and $\mathrm{Pb}^{53+}$ under perpendicular impact. The $\mathrm{Pb}^{53+}$ ions desorbed more molecules than the lower charge state lead ions of the same energy. It was concluded [30] that this effect is probably linked to the dependence of sputtering on the stopping power, which scales with the charge state. At HLI, no yield variation was measured for $1.4 \mathrm{MeV} / \mathrm{u} \mathrm{Xe}^{+19 \cdots+21}$ ions [45]. This result is not surprising since the charge state difference was very small in comparison to the lead-ion experiments at CERN. More systematic measurements to understand the mechanism of the heavy-ion charge state dependence of the desorption yields have not been done so far in the $\mathrm{MeV} / \mathrm{u}$ to $\mathrm{GeV} / \mathrm{u}$ energy range.

\section{Energy scaling}

A better knowledge about the energy dependence of the ion desorption is important not only for the operation of existing heavy-ion machines, but also for the plans for new accelerator projects.

At the GSI-HHT cave of SIS 18, first high-energy measurements with different ion energies (15-1000 MeV/u) were performed in September 2004 [35]. Several stainless steel, aluminum, and copper samples were bombarded with $\mathrm{U}^{73+}$ ions under perpendicular impact $\left(\theta=0^{\circ}\right)$. It was found that the desorption yields $\left(\approx 10^{2}-\right.$ $10^{3}$ molecules $/ \mathrm{U}^{73+}$ ion) decreased for all target materials with increasing projectile energy up to $100 \mathrm{MeV} / \mathrm{u}$ [52]. The measured pressure rises $(\Delta p)$ were small in comparison to the limit pressure of the baked vacuum system without ion bombardment. At higher energies of $408 \mathrm{MeV} / \mathrm{u}$ and $1 \mathrm{GeV} / \mathrm{u}$ no more pressure rise could be measured. An upper limit for the effective desorption yields for these energies was given for all target materials to be less than 200 molecules per incident $\mathrm{U}^{73+}$ ion.

A second experiment was performed in HHT in August 2005 to confirm the observed energy dependence of the desorption yields [36]. That time $40-100 \mathrm{MeV} / \mathrm{u} \mathrm{Ar}^{10+}$ ions bombarding a Conflat ${ }^{\mathrm{TM}}$ stainless steel flange under perpendicular impact were used for energy dependent desorption studies. The 2005 desorption experiment with $\mathrm{Ar}^{10+}$ confirmed the energy scaling of the yields previously measured with $\mathrm{U}^{73+}$; yields of $\approx 4$ 47 molecules $/ \mathrm{Ar}^{10+}$ ion were measured.

At LBNL and LLNL experiments were performed with $\mathrm{K}^{+}$ions with energies between 70 and $1000 \mathrm{keV}$ impacting under grazing incidence $\left(\theta=84.0^{\circ}-85.5^{\circ}\right)$ onto stainless steel. The measured yields of $\approx 10^{3}-10^{4}$ molecules $/ \mathrm{K}^{+}$ were found to increase with ion energy.

The energy scaling was also measured recently at TSL using $\mathrm{Ar}^{8+}, \mathrm{Ar}^{9+}$, and $\mathrm{Ar}^{12+}$ ions with energies of 5, 9.7, and $17.7 \mathrm{MeV} / \mathrm{u}$ [47]. The measured stainless steel yields ranged from 267 to 98 molecules/Ar ion decreasing with increasing projectile energy following the same energy dependence as previously measured with higher-energy Ar ions at GSI. A paper combining the GSI and TSL results about the energy scaling of the ion-induced desorption yield for perpendicular collisions of Ar and $U$ with stainless steel in the energy range of 5 and $100 \mathrm{MeV} / \mathrm{u}$ is in preparation [53].

A summary of the GSI and LBNL results is displayed in Fig. 4. It is clearly visible that the measured desorption yields decrease for increasing $\mathrm{U}$ and Ar projectile energies, following roughly a $\left(d E_{e} / d x\right)^{2}$ scaling of $\eta$. The same behavior is observed for the low-energy $\mathrm{K}^{+}$ions, the yields also scale with the electronic energy loss $\left(d E_{e} / d x\right)^{n}$ with $n=2$. One has to pay attention with the determination and interpretation of the $n$ value since the number of experimental data points is very limited and the shape of the $\left(d E_{e} / d x\right)^{n}$ curve for the $\mathrm{U}$ data does not significantly change if the power $n$ is varied between 2 and 3 .

The scaling of the heavy-ion-induced desorption yields with the electronic energy loss with a power of $n \geq 2$ indicates a microscopic thermally moderated desorption process as introduced many years ago by the Thermal Spike Model [54]. This one-dimensional model has been recently extended to calculate and predict ion-induced desorption yields for different projectile-target systems $[45,55]$. A summary of the experimental ERDA studies researched at GSI and their findings about the mechanism(s) of heavy-ion-induced molecular desorption is beyond the scope of this article but can be found elsewhere $[42,45,56]$.

\section{E. Summary of measured desorption yields}

An overview of available data (August 2008) for heavyion-induced desorption yields, measured as a function of the ion energy and comprising different types of ions, charge states, target types, materials, and different impact angles, is shown in Fig. 5. Effective molecular desorption yields derived from dedicated beam line experiments (HCX: $\mathrm{K}^{+}$, LINAC 3: $\mathrm{Pb}^{53+}$, HLI: $\mathrm{Pb}^{27+}, \mathrm{Zn}^{10+}$, $\mathrm{Xe}^{18+\ldots 21+}$, TSL: $\mathrm{Ar}^{8+\ldots 12+}$, HHT: $\mathrm{Ar}^{10+}, \mathrm{U}^{73+}$, SPS: $\mathrm{In}^{49+}$ ) are compared with results obtained from machine experiments (AGS: $\mathrm{Au}^{31+}$, SIS 18: $\mathrm{U}^{28+}$, RHIC: $\mathrm{U}^{73+}$, $\mathrm{Cu}^{29+}$ ).

It is important to note that one has to carefully distinguish between the low-energy $(\mathrm{MeV} / \mathrm{u})$ and the highenergy results because the loss mechanisms are not the same. For machines like AGS Booster, LEIR, and SIS 18 charge-exchange processes lead to ion beam-loss induced desorption with grazing impact angles in the mrad range. 

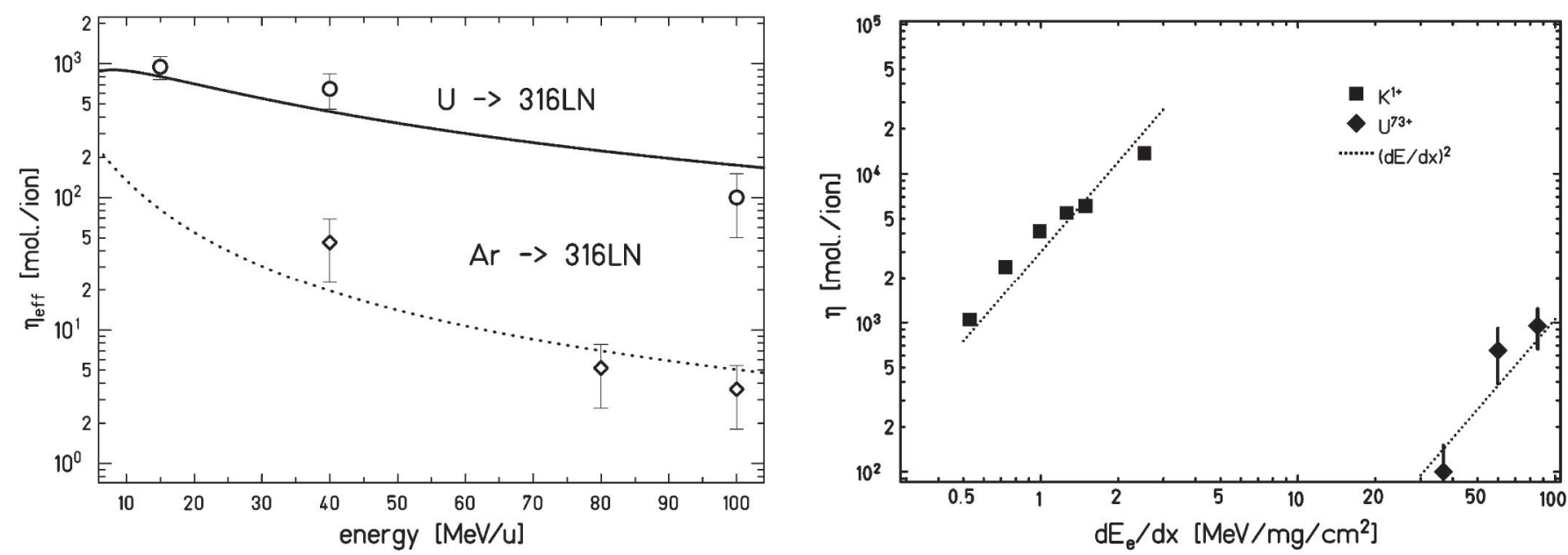

FIG. 4. Left: Desorption yields (points) versus ion energy measured for high-energy $\mathrm{U}^{73+}$ and $\mathrm{Ar}^{10+}$ ions impacting perpendicularly onto $316 \mathrm{LN}$ stainless steel targets. For comparison, the calculated and scaled electronic energy losses $(d E / d x)^{2}$ are shown for both projectile-target systems (lines) [36,46]. Right: Desorption yields (points) versus electronic energy loss (dashed lines) measured for low-energy $\mathrm{K}^{+}$and high-energy $\mathrm{U}^{73+}$ ions; square points: data for $\mathrm{K}^{+}$ions with energies between 70 and $1000 \mathrm{keV}$ impacting under grazing angle $\left(\theta=84.0^{\circ}-85.5^{\circ}\right)$ onto stainless steel; diamond points: SIS 18 data for $\mathrm{U}^{73+}$ ions with energies 15 , 40, and $100 \mathrm{MeV} / \mathrm{u}$ impacting perpendicularly $\left(\theta=0^{\circ}\right)$ onto stainless steel. The dashed curves indicate the power law $(n=2)$ for the electronic component of $d E / d x$ [37].

The loss regions can be rather precisely known and mitigation techniques implemented. The situation is different with fully stripped heavy-ion beams in RHIC and the SPS where losses are dominated by nonlinear dynamics and nuclear scattering, which can yield much smaller impact angles in the $\mu \mathrm{rad}$ range.
The large spread in ion-desorption yields, measured for fixed energy $\mathrm{Pb}^{53+}$ ions with grazing angle impact, is quite remarkable (Fig. 5). The yield variation is about 3 orders of magnitude due to different surface preparation techniques and coatings on stainless steel. As mentioned earlier, and as can also be seen in Fig. 5, perpendicular ion-loss de-

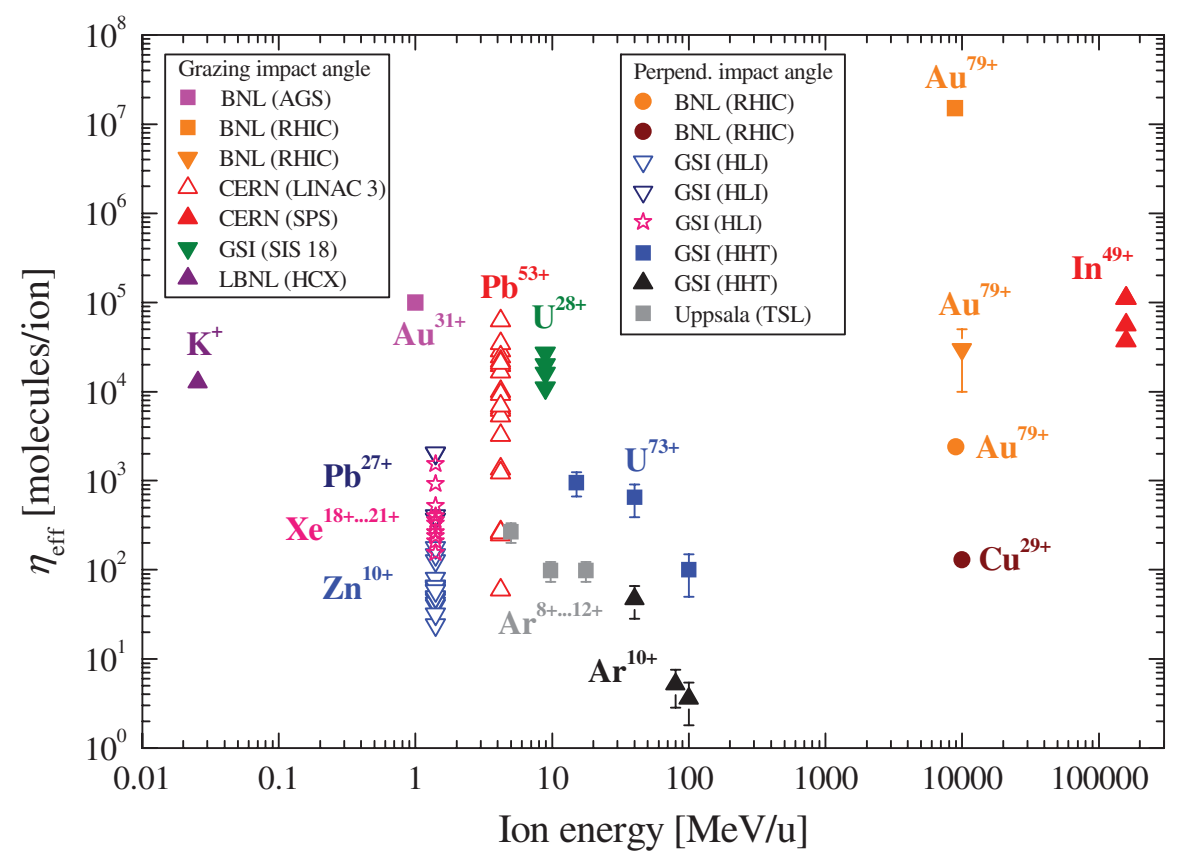

FIG. 5. (Color) Overview of heavy-ion-induced desorption data (status August 2008) classified in experiments with either grazing or perpendicular ion-impact angles. The measurements were made at BNL [5,22,23], CERN [29-31], GSI [7,33,36,45,46,53], LBNL [37], and Uppsala [47,53]. 
sorption rates are lower than for grazing incidence angles. These results are used for ion collimator designs.

A new and important aspect for a more fundamental understanding of the desorption yields, but also for practical accelerator applications, is the energy dependence of the desorption which scale as $\eta=k\left(d E_{e} / d x\right)^{n}$ with $n \geq 2$ and a scaling factor $k$. The decrease of Ar and $\mathrm{U}$ ion yields with increasing projectile energy, measured for perpendicular impact, is also visible in Fig. 5. The influence of the electronic energy loss on $\eta$ has important consequences for synchrotrons: the ion-induced desorption is at its maximum for projectile energies close to the corresponding energy of the Bragg peak with the prospect that pressure rises should decrease during a machine acceleration cycle to higher energies. Ion injection energies into synchrotrons should be, if possible, high enough and acceleration cycles as short as possible in order to avoid ioninduced pressure rise problems. Ion injection losses are of course also a major concern and should be kept as low as feasible in order to increase achievable intensities.

\section{F. Mitigation techniques}

The avalanchelike lead-ion-induced molecular desorption observed at LEAR was systematically studied at LINAC 3 to design and build the LEIR vacuum system, which required an average dynamic pressure (in presence of a circulating lead-ion beam) in the low $10^{-12}$ Torr range [13]. Some methods to reduce the large pressure rises were first found at LINAC 3 and consequently implemented in LEIR [14]. To obtain very clean surfaces after in situ bakeout and low dynamic gas loads under lead-ion bombardment, the LEIR stainless steel vacuum system was NEG coated with TiZrV films wherever possible. This first mitigation technique provides a high pumping speed for LEIR.

The second mitigation is based on the concept to intercept lost lead ions onto special collimators. Cross section calculations had shown that electron capture of the circulating $\mathrm{Pb}^{54+}$ beam would be the dominant loss mechanism producing charge-exchanged $\mathrm{Pb}^{53+}$ ions [13]. In order to prevent these ions to impact under grazing angle onto the vacuum chamber walls, it was proposed to install special absorbers (low outgassing under heavy-ion impact) and lost ions should bombard these collimators under perpendicular impact to minimize the desorption yields $[13,30,51]$.

In total eight LEIR collimators, four movable and four fixed, were installed in 2004/5. They consist of stainless steel platelets (316LN) coated with a $30 \mu \mathrm{m}$ thick gold film onto a $1 \mu \mathrm{m}$ thin diffusion barrier. The gold thickness was chosen to exceed the penetration depth of $4.2 \mathrm{MeV} / \mathrm{u}$ lead ions at normal incidence, which is about $20 \mu \mathrm{m}$. The noble metal coating was chosen according to pressure rise and XPS studies at CERN where a correlation between the measured desorption yields and the surface contaminations with $\mathrm{C}$ and $\mathrm{O}$ was found [57]. A picture of a LEIR collimator, installed at the end of a bending magnet, is shown in Fig. 6.

During machine commissioning in 2006, no evidence was found that the accumulated $\mathrm{Pb}^{54+}$ ion intensity in LEIR was limited by a dynamic vacuum degradation. Beam lifetimes up to $14 \mathrm{~s}$, including losses due to recombination in the electron cooler and interactions with the residual gas, were measured and almost twice the intensity needed for nominal LHC operation could be accumulated using long accumulation plateaus [58]. Therefore, one can conclude that the applied mitigation techniques of NEG coating and perpendicular ion loss onto gold-coated, oxide layer free collimators are successful and that beam-loss induced desorption is not an operational issue for LEIR since the 2006 run.

At GSI a so-called ion-catcher system was chosen to stabilize the dynamic pressure rises in SIS 18. Two prototypes were recently installed in two sections of the synchrotron and successfully tested during machine studies with $\mathrm{U}^{28+}$ beam [59]. A schematic collimator drawing is displayed in Fig. 6.

The prototype catcher consists of one wedge-shaped and one block-shaped copper absorber, both coated with a few $100 \mathrm{~nm}$ thin gold layer onto an underlying nickel layer, which acts as a diffusion barrier during the UHV bakeout [60]. The catcher absorbers can be moved transversally; they are enclosed in a secondary vacuum chamber which is coated (as the main chamber) with TiZrV. Ions are lost under perpendicular impact onto the block collimator and under grazing angle onto the wedge collimator. The reported desorption rates of $\eta_{\text {block }} \approx 55$ molecules/ion and $\eta_{\text {wedge }} \approx 278$ molecules/ion [59] confirmed the preference for perpendicular beam loss in SIS 18. The basic concept is therefore very similar to the LEIR case. The prototype ion-catcher design has been simplified: it now contains only one in situ bakable gold-coated copper-block absorber, an instrumentation feedthrough for diagnostics and no movable mechanics inside the vacuum [61].

It should be noted that the design of the core part of the GSI ion catcher, the low-outgassing gold-coated copper block, is a result of research and development studies with the ion beam analysis technique UHV-ERDA $[42,45,56]$. It was shown that the heavy-ion-induced desorption is a surface effect where the projectile releases adsorbed gas from the target with only a minor contribution of sputtered $\mathrm{C}$ and $\mathrm{O}$. In addition, the process is target sensitive which is also characterized by the observed $\left(d E_{e} / d x\right)^{2}$ scaling [35-37,52]. A direct consequence of these ERDA results was the choice of the collimator materials, specifically important for SIS 18 but also of more general interest for heavy-ion machines: it should be a conductive material with a clean metallic surface. In that respect the LEIR choice of a thick gold layer deposited onto a stainless steel 

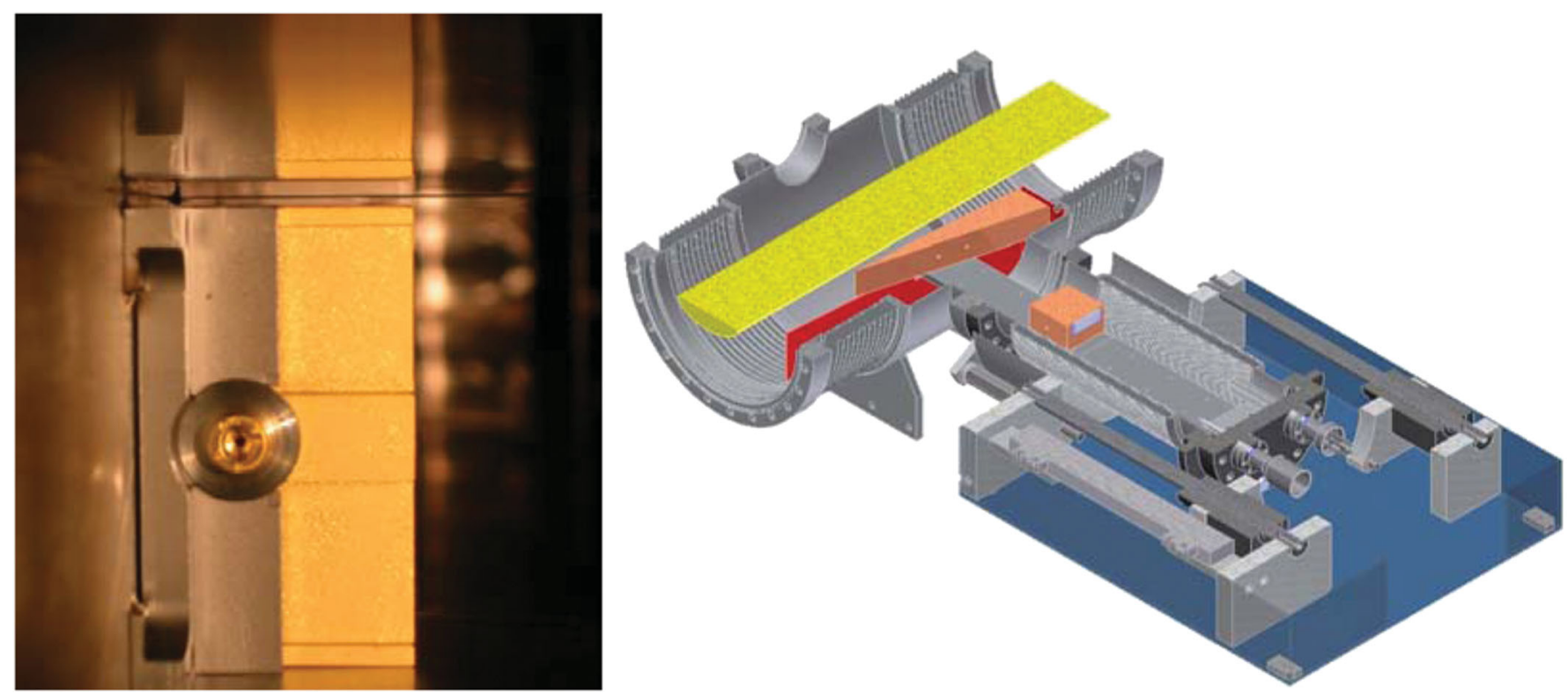

FIG. 6. (Color) Left: Photograph of a $30 \mu \mathrm{m}$ gold-coated $316 \mathrm{LN}$ stainless steel collimator to collect lost $4.2 \mathrm{MeV} / \mathrm{u} \mathrm{Pb}{ }^{53+}$ ions. The collimator is screwed on the back face onto a stainless steel support which is spot welded at the end of each LEIR bending magnet vacuum chamber [14]. Right: Horizontal cut through the installed SIS 18 ion-catcher prototype. Yellow: beam; red: secondary chamber; brown: beam absorbers [59].

substrate was a similar or equivalent approach to the present GSI design of a thin gold layer on copper [62].

Apart from the new collimator system, other mitigation techniques have been started for the improvement of SIS 18, this includes an important UHV system upgrade [63] with new NEG-coated dipole and quadrupole vacuum chambers but also the exchange of the injection system [64] which has been redesigned and rebuilt [65].

Apparently, a combination of reduced injection losses, an increased ramp rate for fast ion acceleration, a very large distributed pumping speed together with an efficient ion-catcher system is required to increase the number of extracted SIS 18 particles from presently $6.5 \times 10^{9} \mathrm{U}^{28+}$ ions [66] to the desired value of $\approx 10^{12+}$ for FAIR.

At BNL, it was proposed to test so-called antigrazing rings to mitigate grazing angle projectile collisions in RHIC [25]. The basic idea is that all particles should be lost with near-perpendicular impact on these absorbers, a special surface coating was not reported. A set of bare stainless steel rings was installed in a warm section of the machine and tested with protons in 2005 [67]. One found that the rings were effective in raising the electron cloud threshold and in reducing the dynamic pressure rise. Further improvements were expected for gold beams due to their larger secondary electron and desorption yields but not experimentally tested. It was decided not to install more antigrazing rings in the machine and to avoid the potential risk to increase detector background signals in the experiments, but to rely mostly on the RHIC vacuum system upgrade with NEG-coated beam pipes [68].
Finally, the method of beam cleaning or scrubbing is another mitigation technique. Here one uses the fact that a continuous heavy-ion bombardment of the vacuum chamber walls, or any other machine device, yields to a reduction of the pressure rise with time. The feasibility has been demonstrated, for example in LINAC 3 and at HLI. Typical scrubbing measurements are displayed in Fig. 7. The initial pressure rise of $\Delta p=10^{-7}$ Torr, measured for $4.2 \mathrm{MeV} / \mathrm{u}$ lead ions bombarding a vacuum fired $\left(950^{\circ} \mathrm{C}\right.$, $2 \mathrm{~h}) 316 \mathrm{LN}$ stainless steel accelerator-type vacuum chamber under grazing angle, was reduced by about 2 orders of magnitude after 60 hours of beam scrubbing which corresponded to a dose of about $7 \times 10^{12}$ ions $/ \mathrm{cm}^{2}$. It is also interesting to note that the $304 \mathrm{~L}$ stainless steel target, which was not vacuum fired, provided the lowest initial pressure rise (see Fig. 7) and the ERDA analysis showed the lowest surface contamination with oxygen and carbon (see Fig. 3). The scrubbing time depends of course on the provided projectile flux and the minimum pressure rise to be achieved, the higher the ion dose the shorter the necessary bombardment time.

Apart from the pressure rise reduction with ion dose, the composition of the desorbed gas can change during the scrubbing period. It was found that $\mathrm{CO}$ and $\mathrm{CO}_{2}$ were often the dominant desorbed gas at the beginning of the scrubbing run while $\mathrm{H}_{2}$ was dominating at the end of the continuous ion bombardment. In general, the changed gas composition from heavier to lighter molecules is beneficial for the beam lifetime in any heavy-ion accelerator. 


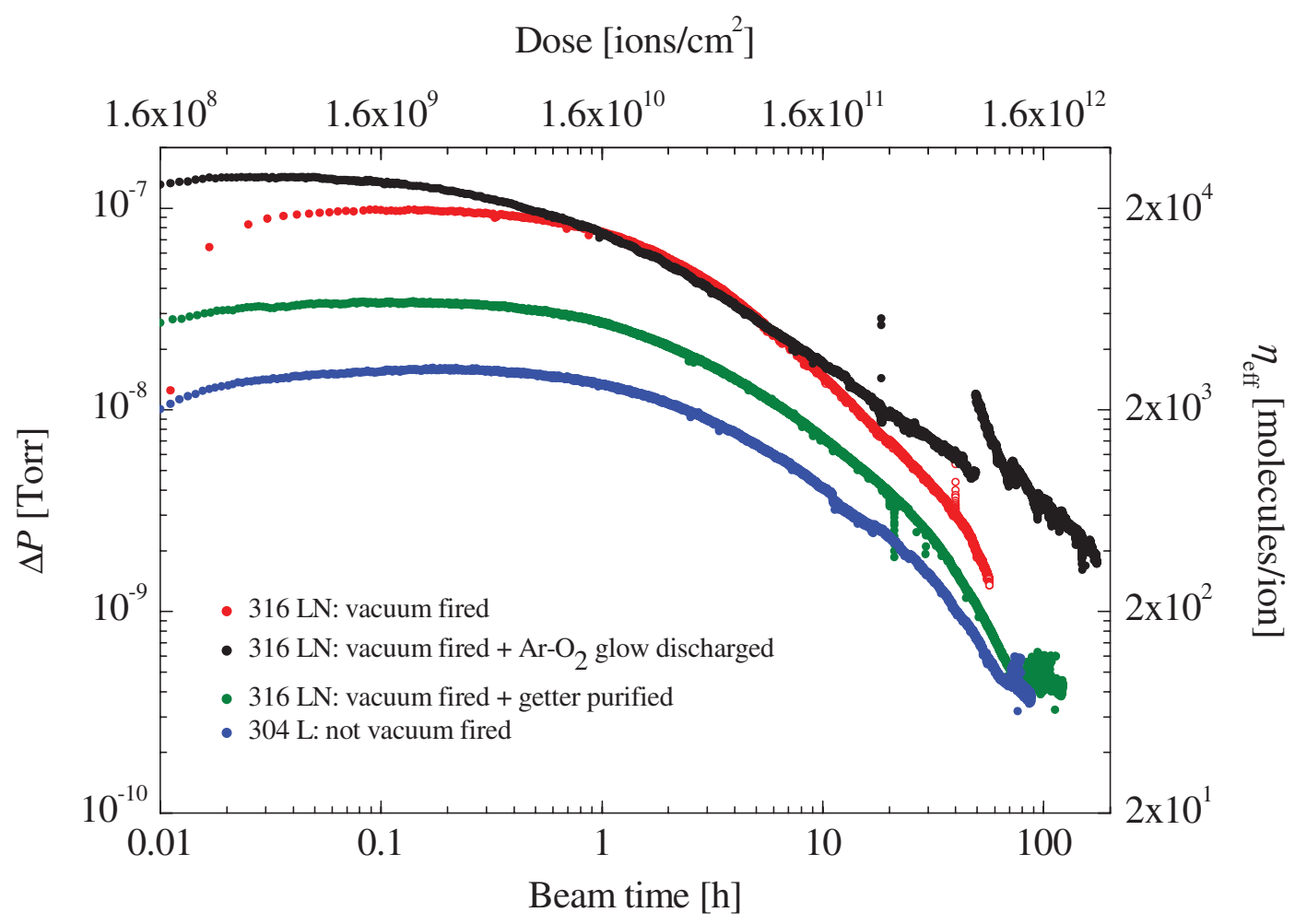

FIG. 7. (Color) Beam cleaning measurements for four different stainless steel (316LN, 304L) vacuum chambers continuously bombarded with $1.5 \times 10^{9} \mathrm{~Pb}^{53}$ ions (per shot) under $\theta=89.2^{\circ}$ grazing incidence. The shown desorption measurements were done with $4.2 \mathrm{MeV} / \mathrm{u}$ lead ions at LINAC 3; all four vacuum chambers were cut afterwards and samples of each chamber were studied with ERDA [70]. The obtained ERDA results are displayed in Fig. 3.

\section{CONCLUSIONS AND FUTURE STUDIES}

During the past decade, intense experimental studies on the heavy-ion-induced molecular desorption were performed in several particle accelerator laboratories worldwide. A lot of progress has been made in the physics understanding of the ion-desorption process and several mitigation techniques were developed and implemented in some synchrotrons. For ambient temperature targets only a few but important questions remain to be answered. Future studies should probably focus on at least two aspects. First, more particle accelerator relevant experiments are needed to investigate the heavy-ion-induced molecular desorption of NEG coatings, which are by now used in several machines. It is proposed to further research the ion-desorption behavior of TiZrV films and to compare fully activated with saturated getter films. First experiments have already been done at CERN and in Uppsala. A second domain is the ion-induced desorption of cryogenic surfaces. With the exception of one cold-bore experiment at CERN [69], cold surfaces are nearly unstudied using highenergy ions. Cryogenic experiments are motivated by the near-future heavy-ion operation of the LHC and later at FAIR.

\section{ACKNOWLEDGMENTS}

I would like to thank many colleagues from different laboratories such as Berkeley, Brookhaven, CERN, GSI, and Uppsala for their collaboration during the past years. The reviewed results are based on their hard and dedicated work. I want to acknowledge the fruitful collaboration with the GSI vacuum group, especially M.C. Bellachioma, M. Bender, H. Kollmus, A. Krämer, and H. ReichSprenger who were involved in many of the quoted experiments. During the past years I also greatly benefited from discussions with many people from CERN and other laboratories including $\mathrm{C}$. Benvenuti, O. Boine-Frankenheim, S. Calatroni, C. Carli, M. Chanel, P. Chiggiato, M. Kireeff Covo, N. Hilleret, I. Efthymiopoulos, W. Fischer, O. Gröbner, E. Hedlund, J. M. Jimenez, J. M. Laurent, O. B. Malyshev, A. Molvik, E. Mustafin, P. Costa Pinto, C. Omet, K. Schindl, P. Spiller, P. Strubin, M. Taborelli, P. Thieberger, H. Vincke, L. Westerberg, and S. Y. Zhang. The desorption experiments at CERN could not have been done without several colleagues in the vacuum group and the linac team; special thanks to D. Allard, J. Broere, R. Hajdas, J. Hansen, C. Hill, D. Küchler, M. O’Neil, E. Page, R. Scrivens, and S. Southern for their support, excellent 
collaboration, and the very reliable operation of LINAC 3. Last but not least I want to thank many colleagues from the CERN workshop and cleaning section for their continuous support, the build of the LINAC 3 test stand including the fabrication, cleaning, and coating of various vacuum chambers and samples.

[1] O. Gröbner and R. S. Calder, in Proceedings of the 1973 Particle Accelerator Conference, San Francisco, 1973 [IEEE Trans. Nucl. Sci., NS-20, 760 (1973)]; Report No. CERN/ISR-VA/73-15, 1973.

[2] R. Calder, E. Fischer, O. Gröbner, and E. Jones, in Proceedings of the 9th International Conference on High Energy Accelerators, Stanford, 1974, p. 70; Report No. CERN/ISR-VA/74-26, 1974.

[3] J. Bosser et al., Part. Accel. 63, 171 (1999).

[4] S. Y. Zhang and L. A. Ahrens, in Proceedings of the 6th European Particle Accelerator Conference, Stockholm, 1998 (IOP, London, 1998), p. 2149.

[5] S. Y. Zhang and L. A. Ahrens, in Proceedings of the 18th Particle Accelerator Conference, New York, 1999 (IEEE, New York, 1999), p. 3294.

[6] A. Krämer, O. Boine-Frankenheim, I. Hoffmann, H. Reich Sprenger, and P. Spiller, in Proceedings of the 8th European Particle Accelerator Conference, Paris, 2002 (EPS-IGA and CERN, Geneva, 2002), p. 2547.

[7] E. Mustafin, O. Boine-Frankenheim, I. Hoffmann, H. Reich Sprenger, and P. Spiller, Nucl. Instrum. Methods Phys. Res., Sect. A 510, 199 (2003).

[8] W. Fischer et al., in Proceedings of the 8th European Particle Accelerator Conference, Paris, 2002, Ref. [6], p. 1485.

[9] W. Fischer, M. Blaskiewicz, J. M. Brennan, H. Huang, H.-C. Hseuh, V. Ptitsyn, T. Roser, P. Thieberger, D. Trbojevic, J. Wei, S. Y. Zhang, and U. Iriso, Phys. Rev. ST Accel. Beams 11, 041002 (2008).

[10] G. Logan et al., Nucl. Instrum. Methods Phys. Res., Sect. A 544, 1 (2005); 577, 1 (2007).

[11] A. W. Molvik, M. Kireeff Covo, F. M. Bieniosek, L. Prost, P. A. Seidl, D. Baca, A. Coorey, and A. Sakumi, Phys. Rev. ST Accel. Beams 7, 093202 (2004).

[12] Proceedings of the 13th ICFA Beam Dynamics MiniWorkshop on Beam Induced Pressure Rise in Rings, Brookhaven National Laboratory, 2003, http://www. c-ad.bnl.gov/icfa/.

[13] E. Mahner, CERN Report No. LHC/VAC-TN-2002-04, 2002.

[14] E. Mahner, Vacuum 81, 727 (2007).

[15] www.fair-center.de.

[16] K. Blasche et al., GSI Scientific Report 2001, p. 195 (2002).

[17] K. Blasche et al., GSI Scientific Report 2002, p. 193 (2003).

[18] E. Mustafin, O. Boine-Frankenheim, I. Hofmann, H. Reich-Sprenger, and P. Spiller, GSI Scientific Report 2002, p. 200 (2003).

[19] K. Blasche et al., GSI Scientific Report 2003, p. 209 (2004).
[20] S. Y. Zhang et al., in Proceedings of the 9th European Particle Accelerator Conference, Lucerne, 2004 (EPSAG, Lucerne, 2004), p. 944.

[21] H. Huang, W. Fischer, P. He, H. C. Hseuh, U. Iriso, V. Ptitsyn, D. Trbojevic, J. Wei, and S. Y. Zhang, in Proceedings of the 10th European Particle Accelerator Conference, Edinburgh, Scotland, 2006 (EPS-AG, Edinburgh, Scotland, 2006), p. 583.

[22] S. Y. Zhang et al., in Proceedings of the 20th Particle Accelerator Conference, Portland, OR, 2003 (IEEE, New York, 2003), p. 54.

[23] W. Fischer, H.C. Hseuh, U. Iriso, and E. Mustafin, Proceedings ECLOUD'07, International Workshop on Electron Cloud Effects, Daegu, Korea, KEK Proceedings 2007-10 (KEK, Tsukuba, 2007), p. 76, and references therein.

[24] H. C. Hseuh, M. Mapes, L. A. Smart, R. Todd, and D. Weiss, in Proceedings of the 21st Particle Accelerator Conference, Knoxville, 2005 (IEEE, Piscataway, NJ, 2005), p. 2977.

[25] P. Thieberger, W. Fischer, H. Hseuh, V. Ptitsyn, L. P. Snydstrup, D. Trbojevic, and S. Y. Zhang, Phys. Rev. ST Accel. Beams 7, 093201 (2004).

[26] E. Hedlund, E. Edqvist, H. Kollmus, M. C. Bellachioma, H. Reich-Sprenger, and A. Krasnov, Nucl. Instrum. Methods Phys. Res., Sect. A 586, 377 (2008).

[27] J. Hansen, J.-M. Laurent, N. Madsen, and E. Mahner, CERN Report No. LHC/VAC-TN-2001-07, 2001.

[28] M. Chanel, J. Hansen, J.-M. Laurent, N. Madsen, and E. Mahner, in Proceedings of the 19th Particle Accelerator Conference, Chicago, Illinois, 2001 (IEEE, Piscataway, NJ, 2001), p. 2165.

[29] E. Mahner, J. Hansen, D. Küchler, M. Malabaila, and M. Taborelli, in Proceedings of the 8th European Particle Accelerator Conference, Paris, 2002, Ref. [6], p. 2568.

[30] E. Mahner, J. Hansen, J.-M. Laurent, and N. Madsen, Phys. Rev. ST Accel. Beams 6, 013201 (2003).

[31] E. Mahner, J. Hansen, D. Küchler, M. Malabaila, and M. Taborelli, Phys. Rev. ST Accel. Beams 8, 053201 (2005).

[32] E. Mahner, I. Efthymiopoulos, J. Hansen, E. Page, and H. Vincke, Phys. Rev. ST Accel. Beams 7, 103202 (2004).

[33] M. Bender, Diploma thesis, Fachhochschule Wiesbaden, 2003.

[34] M. Bender, H. Kollmus, and A. Krämer, GSI Scientific Report 2003, p. 219 (2004).

[35] H. Kollmus, M. Bender, A. Krämer, M. C. Bellachioma, E. Mahner, L. Westerberg, E. Hedlund, O. B. Malyshev, and H. Reich-Sprenger, GSI Scientific Report 2004, p. 316 (2005).

[36] M. Bender, H. Kollmus, A. Krämer, E. Mahner, and E. Hedlund, GSI Scientific Report 2005, p. 109 (2006).

[37] A. W. Molvik, H. Kollmus, E. Mahner, M. Kireeff Covo, M. C. Bellachioma, M. Bender, F. M. Bieniosek, E. Hedlund, A. Krämer, J. Kwan, O. B. Malyshev, L. Prost, P. A. Seidl, G. Westenskow, and L. Westerberg, Phys. Rev. Lett. 98, 064801 (2007).

[38] P. Thieberger, J. G. Alessi, H. Abendroth, C. Carlson, H. C. Hseuh, L.P. Snydstrup, and S. Y Zhang (private communication). 
[39] E. Mustafin, O. Boine-Frankenheim, I. Hofmann, H. Reich-Sprenger, and P. Spiller, Nucl. Instrum. Methods Phys. Res., Sect. A 510, 199 (2003).

[40] P. J. Spiller, K. Blasche, P. Hülsmann, A. Krämer, H. Ramakers, and H. Reich-Sprenger, in Proceedings of the 9th European Particle Accelerator Conference, Lucerne, 2004, Ref. [20], p. 1180.

[41] A. W. Molvik, M. K. Kireeff Covo, F. M. Bieniosek, L. Prost, P. A. Seidl, D. Baca, A. Coorey, and A. Sakumi, Phys. Rev. ST Accel. Beams 7, 093202 (2004).

[42] H. Kollmus, M. Bender, W. Assmann, A. Krämer, M. C. Bellachioma, and H. Reich-Sprenger, Vacuum 82, 402 (2008).

[43] E. Mahner, I. Efthymiopoulos, J. Hansen, E. Page, and H. Vincke, in Proceedings of the 9th European Particle Accelerator Conference, Lucerne, 2004, Ref. [20], p. 1633.

[44] H. Kollmus, M. Bender, A. Krämer, and E. Mahner (to be published).

[45] M. Bender, Ph.D. thesis, Johann Wolfgang GoetheUniversität Frankfurt am Main, 2008.

[46] H. Kollmus, M. C. Bellachioma, M. Bender, A. Krämer, J. Kurdal, and H. Reich-Sprenger, in Proceedings of the 10th European Particle Accelerator Conference, Edinburgh, Scotland, 2006, Ref. [21], p. 1426.

[47] E. Hedlund, Ph.D. thesis, Uppsala, 2008.

[48] M. Bender, H. Kollmus, and W. Assmann, in Proceedings of the 10th European Particle Accelerator Conference, Edinburgh, Scotland, 2006, Ref. [21], p. 1423.

[49] W. Assmann, H. Huber, Ch. Steinhausen, M. Dobler, H. Glückler, and A. Weidinger, Nucl. Instrum. Methods Phys. Res., Sect. B 89, 131 (1994).

[50] P. Thieberger, A. L. Hanson, D. B. Steski, V. Zajic, S. Y. Zhang, and H. Ludewig, Phys. Rev. A 61, 042901 (2000).

[51] J. Pasternak, C. Bal, C. Carli, M. Chanel, and E. Mahner, in Proceedings of the 21st Particle Accelerator Conference, Knoxville, 2005, Ref. [24], p. 3816.

[52] H. Kollmus, M. Bender, M. C. Bellachioma, E. Mahner, A. Krämer, L. Westerberg, E. Hedlund, O. B. Malyshev, and H. Reich-Sprenger, in Proceedings of High Intensity and High Brightness Beams, edited by I. Hofmann, J.-M. Lagniel, and R.W. Hasse, AIP Conf. Proc. No. 773 (AIP, Melville, New York, 2005), p. 207.

[53] H. Kollmus, A. Krämer, M. Bender, M. C. Bellachioma, H. Reich-Sprenger, E. Mahner, E. Hedlund, L.
Westerberg, O. B. Malyshev, M. Leandersson, and E. Edquist (to be published).

[54] M. Toulemonde, W. Assmann, C. Trautmann, F. Grüner, H. D. Mieskes, H. Kucal, and Z. G. Wang, Nucl. Instrum. Methods Phys. Res., Sect. B 212, 346 (2003).

[55] M. Bender, H. Kollmus, W. Assmann, R. Dörner, and H. Reich-Sprenger, GSI Scientific Report 2007, p. 103 (2008).

[56] M. Bender, H. Kollmus, and W. Assmann, Nucl. Instrum. Methods Phys. Res., Sect. B 256, 387 (2007).

[57] E. Mahner, J. Hansen, D. Küchler, M. Malabaila, and M. Taborelli, Divisional Report No. CERN AT/2003-6, 2003.

[58] P. Belochitskii et al., in Proceedings of the 10th European Particle Accelerator Conference, Edinburgh, Scotland, 2006, Ref. [21], p. 1876.

[59] C. Omet, H. Kollmus, H. Reich-Sprenger, and P. Spiller, in Proceedings of the 11th European Particle Accelerator Conference, Genoa, 2008 (EPS-AG, Genoa, Italy, 2008), p. 295.

[60] H. Kollmus, M. Bender, W. Assmann, R. Dörner, C. Halfpap, B. Kindler, A. Krämer, B. Lommel, and H. Reich-Sprenger, GSI Scientific Report 2007, p. 102 (2008).

[61] H. Reich-Sprenger and C. Omet (private communication).

[62] M. Bender (private communication).

[63] M. C. Bellachioma, M. Bender, H. Kollmus, A. Krämer, J. Kurdal, and H. Reich-Sprenger, GSI Scientific Report 2007, p. 101 (2008).

[64] P. Spiller et al., GSI Scientific Report 2007, p. 88 (2008).

[65] U. Blell, J. Florenkowski, M. Petryk, and P. Spiller, GSI Scientific Report 2007, p. 90 (2008).

[66] C. Omet and P. Spiller, GSI Scientific Report 2007, p. 91 (2008).

[67] S. Y. Zhang, H. C. Hseuh, P. Thieberger, and D. Trbojevic, Phys. Rev. ST Accel. Beams 8, 123201 (2005).

[68] W. Fischer, M. Blaskiewicz, J. M. Brennan, H. Huang, H. C. Hseuh, V. Ptitsyn, T. Roser, P. Thieberger, D. Trbjojevic, J. Wei, and S. Y. Zhang, Phys. Rev. ST Accel. Beams 11, 041002 (2008).

[69] E. Mahner, M. Bender, and H. Kollmus, in Proceedings of High Intensity and High Brightness Beams, Ref. [52], p. 219; CERN Report No. Vacuum Technical Note 0504, 2005.

[70] W. Assmann and H. Kollmus (private communication). 